\title{
Roy et al.
}

\section{GSA DATA REPOSITORY 2016192}

\section{Dynamic links between rock damage, erosion, and strain in active orogens}

\section{Rock Strength-Erodibility Scaling}

We link processes of fluvial incision to rock strength through the erodibility parameter $k_{b}$. For Experiment 1 we assume homogeneous erodibility independent of the mechanical solution, but for Experiment 2 the strain-softening rheology translates to a scaled increase in erodibility concentrated in shear zones that emerge at peaks of total plastic strain (Figure 1D). Assuming that substrate erodibility is inversely proportional to anelastic strength (Hanson and Simon, 2001; Sklar and Dietrich, 2001), we apply the scaling rule $k_{b}=k_{c} C^{-1 / 2}$, where $C$ is cohesion and $k_{c}$ is a coefficient equal to 0.2 with units $\mathrm{m}^{1 / 2} \mathrm{~s} \mathrm{~kg}^{-1 / 2}$ (Roy et al., 2015b). We elect to use cohesion as our gauge of anelastic strength because of its importance in the MohrCoulomb failure criterion and because of the greater accuracy of measurement over tensile strength in heavily damaged rock (Hoek and Brown, 1980).

\section{Orographic Precipitation Model}

For our purposes we define an orographic model $P_{n}=P_{n-1} e^{-\Psi}\left(1+u S_{s} e^{-\frac{z}{H}}\right)$, in which local annual precipitation $P_{n}$ is a function of the vertical deflection of wind caused by surface slope $S_{s}$ and lateral wind velocity $u$, the change in air temperature with elevation $z$, represented by the e-folding height $H$, and the loss of air moisture with distance traveled over the orogen $\Psi=P_{n-1} /\left(R_{0}-\int_{0}^{n-1} P d x\right)$, where $P_{n-1}$ is annual precipitation at the closest upwind node, $R_{0}$ is annual precipitable water at the western boundary, and $\int_{0}^{n-1} P d x$ is the integral of annual precipitation from boundary to node $n-1$. This model synthesizes the typical heterogeneous 
pattern of orographic precipitation to produce high precipitation rates on the western windward slopes that decrease to the east (Figure 1A), a pattern that amplifies with greater relief.

\section{Stream Power Derivation}

A configuration of the Channel-Hillslope Integrated Landscape Developmental (CHILD) model (Tucker et al., 2001) is used to approximate the physics behind mechanical wear of the substrate under the assumption that rivers can erode bedrock at a rate roughly proportional to unit stream power, or the near-equivalent boundary shear stress, under a supply-limited condition in which all detached bedrock is removed through open flow boundaries (e.g. Howard and Kerby, 1983; Seidl and Dietrich, 1992). Rock strength also plays a critical role in glacial erosion (Becker et al., 2014) and hillslope stability (Brideau et al., 2009), but for simplicity we are limiting our scope to its effects on fluvial incision. A steepest-descent routing algorithm controls the spatial distribution of surface runoff in channels that are embedded as subgrid-scale features. The mechanical and surface processes models cooperatively influence topographic evolution by the equation $\frac{\partial h}{\partial t}=-k_{b} \omega+V_{z}+V_{h} \nabla h$, where the rate of elevation change $\frac{\partial h}{\partial t}$ at any point on a surface depends on spatially variable erodibility $k_{b}$, vertical rock motion relative to baselevel $V_{z}$, lateral topographic advection $V_{h} \nabla h$, and stream power $\omega$ per unit length, where $\omega=$ $k_{t}(Q / W) S_{c}$, a function of the unit weight of water $k_{t}\left(9800 \mathrm{~kg} \mathrm{~m}^{-2} \mathrm{~s}^{-2}\right)$, fluid discharge $Q$, channel width $W$, and channel slope $S_{c}$. Upstream precipitation and drainage area values are integrated for every point in order to calculate fluid discharge. Channel width is calculated using the empirical method (Leopold and Maddock, 1953) $W=k_{w} Q^{0.5}$, where $k_{w}$ is the widthdischarge coefficient set equal to $10 \mathrm{~s}^{0.5} \mathrm{~m}^{-0.5}$. Linear interpolation is used to transfer changes in surface shape between the mechanical model and the surface dynamics model, which implements a finer element resolution with irregular discretization (Lee and Schachter, 1980) in 
order to better capture the scale and geometry in which fluvial erosion influences topography

(Figure 1B).

\section{Table DR1}

Table DR1: Mechanical model parameters; strain softening values to right of arrows active after $20 \%$ plastic shear strain.

Bulk modulus $(\mathrm{Pa})$

Shear modulus $(\mathrm{Pa})$

Density $\left(\mathrm{kg} \mathrm{m}^{-3}\right)$

Friction angle (deg)

Cohesion $(\mathrm{Pa})$

Midcrust plastic yield stress $(\mathrm{Pa})$

Midcrust Decollement slip rate $\left(\mathrm{mm} \mathrm{yr}^{-1}\right)$
$1 \times 10^{10}$

$3 \times 10^{9}$

2700

$35 \rightarrow 30$

$3 \times 10^{7} \rightarrow 1 \times 10^{6}$

$5 \times 10^{7}$

50 


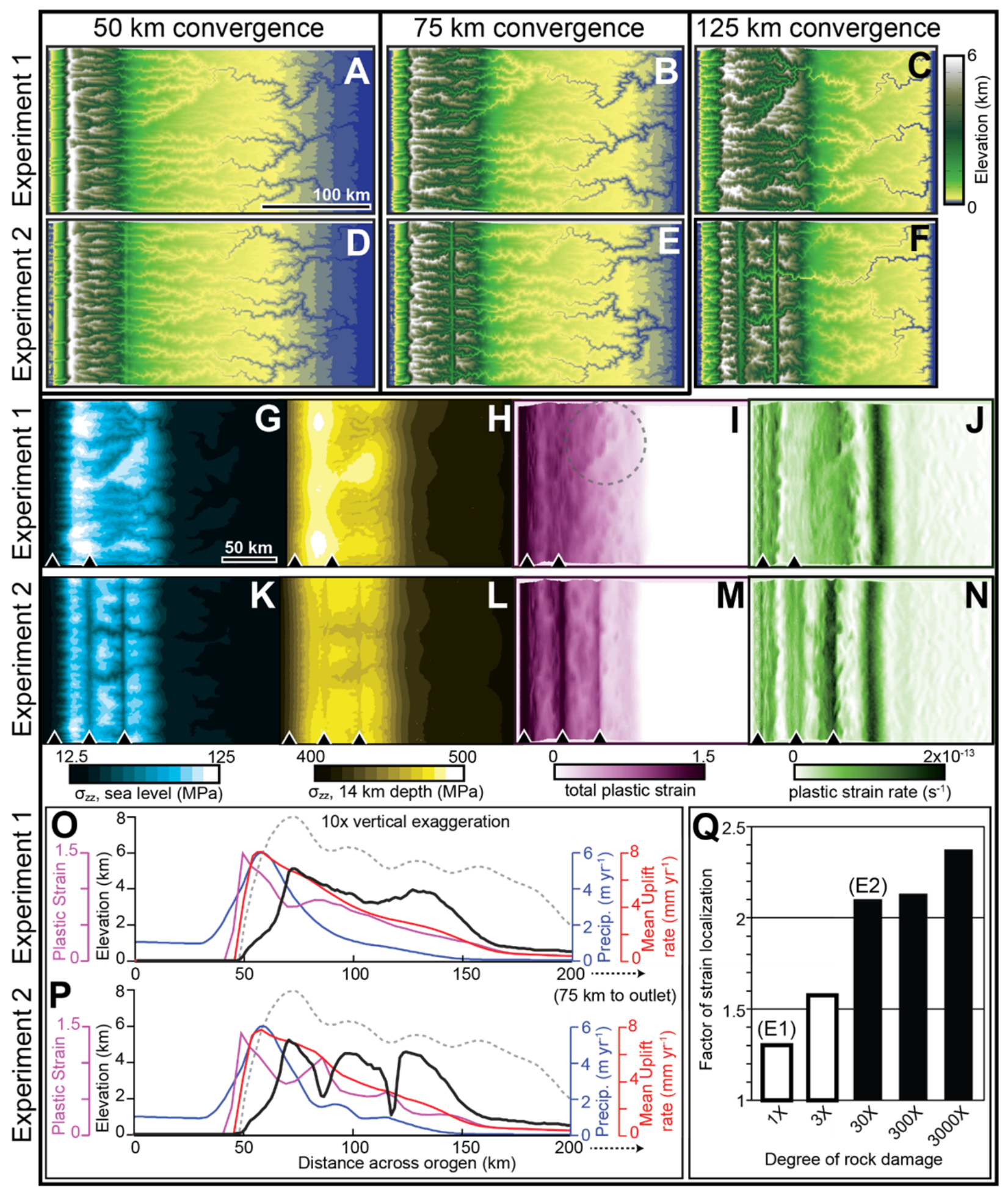

Figure DR1: Topography of Experiment 1 and 2, respectively, at (A, D) $50 \mathrm{~km},(\mathrm{~B}, \mathrm{E}) 75 \mathrm{~km}$, and $(\mathrm{C}, \mathrm{F}) 125 \mathrm{~km}$ of plate convergence. $(\mathrm{G}, \mathrm{K})$ Vertical normal stress at sea level penetrates down to the rheological boundary $(\mathrm{H}, \mathrm{L})$ at $14 \mathrm{~km}$ depth. (I, M) Total plastic strain, and (J, N) instantaneous strain rate fields for Experiment 1 and 2, respectively. Relatively high strain rates 
occur along the indentor front and high strain rate along the growing eastern edge of the orogen for both experiments. Within the orogen of $1 \mathrm{X}$ strain rate is relatively low and more diffuse, but does tend to concentrate approximately $40 \mathrm{~km}$ to the west of the growing edge of the orogen. Strain rate tends to be greatest along the growing eastern edge of the orogen of 30X, but high strain rates also persist in the eroded shear zones even after they have migrated to the interior of the orogen. Arrowheads indicate the location of shear zones. Dashed circle indicates a local topographic effect on plastic strain accommodation. Elevation profiles on cross-section line aa' (Figure 1A) for (O) Experiment 1 and $(\mathrm{P})$ Experiment 2, including precipitation rate, mean uplift rate, and total plastic strain. Grey dashed line indicates topographic profile of a simulation that is rheologically identical to Experiments 1 and 2 but with no erosion. (Q) Plot of strain localization factor versus degree of rock damage. E1: Experiment 1, E2: Experiment 2. White: rivers are dominantly range-perpendicular and dendritic, black: rivers are dominantly range-parallel and structurally confined.

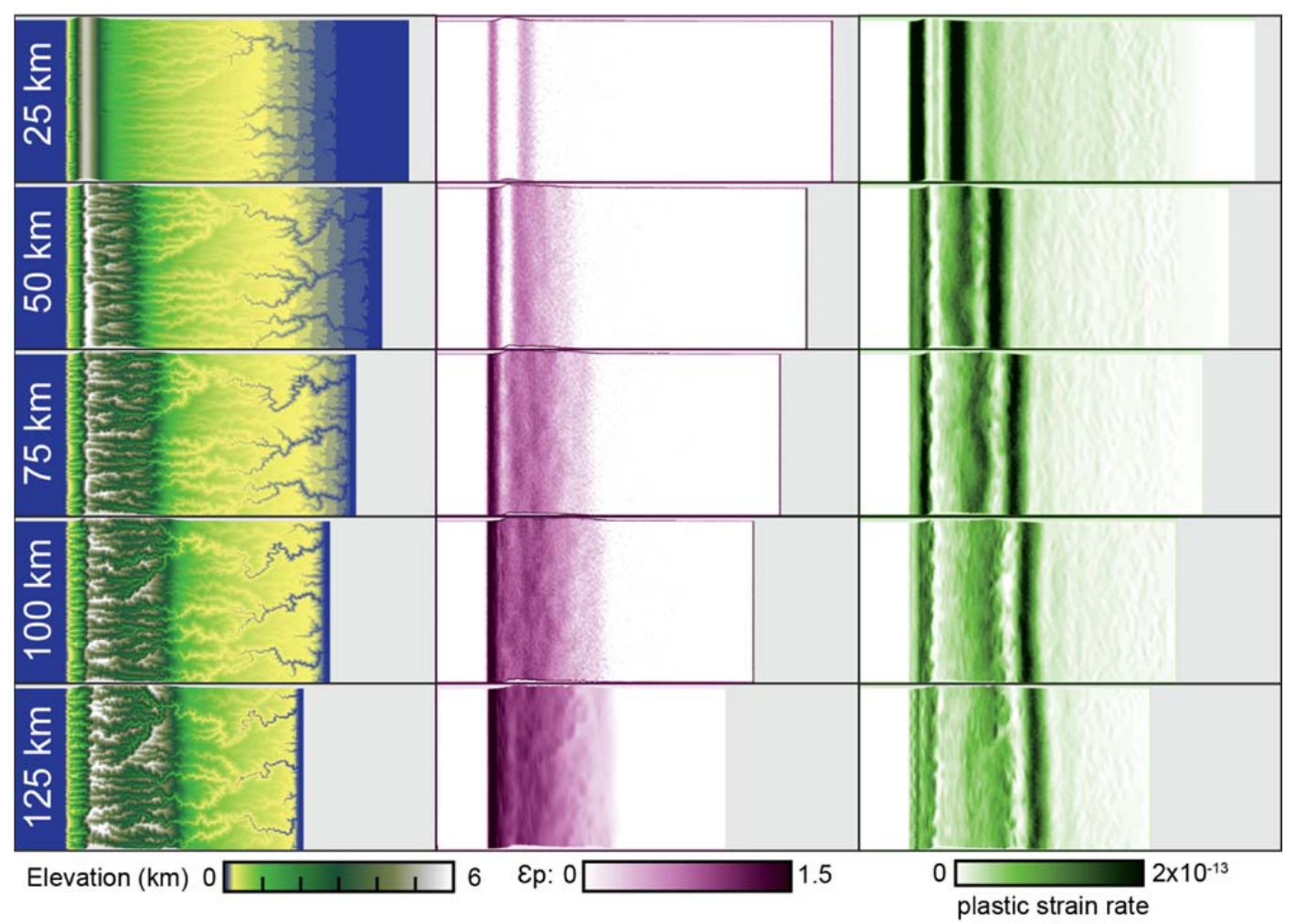

Figure DR2: Experiment 1X supplemental data. By row: 25, 50, 75, 100, $125 \mathrm{~km}$ convergence. By column: elevation, total plastic strain $\left(\mathcal{E}_{\mathrm{p}}\right)$, instantaneous strain rate. 


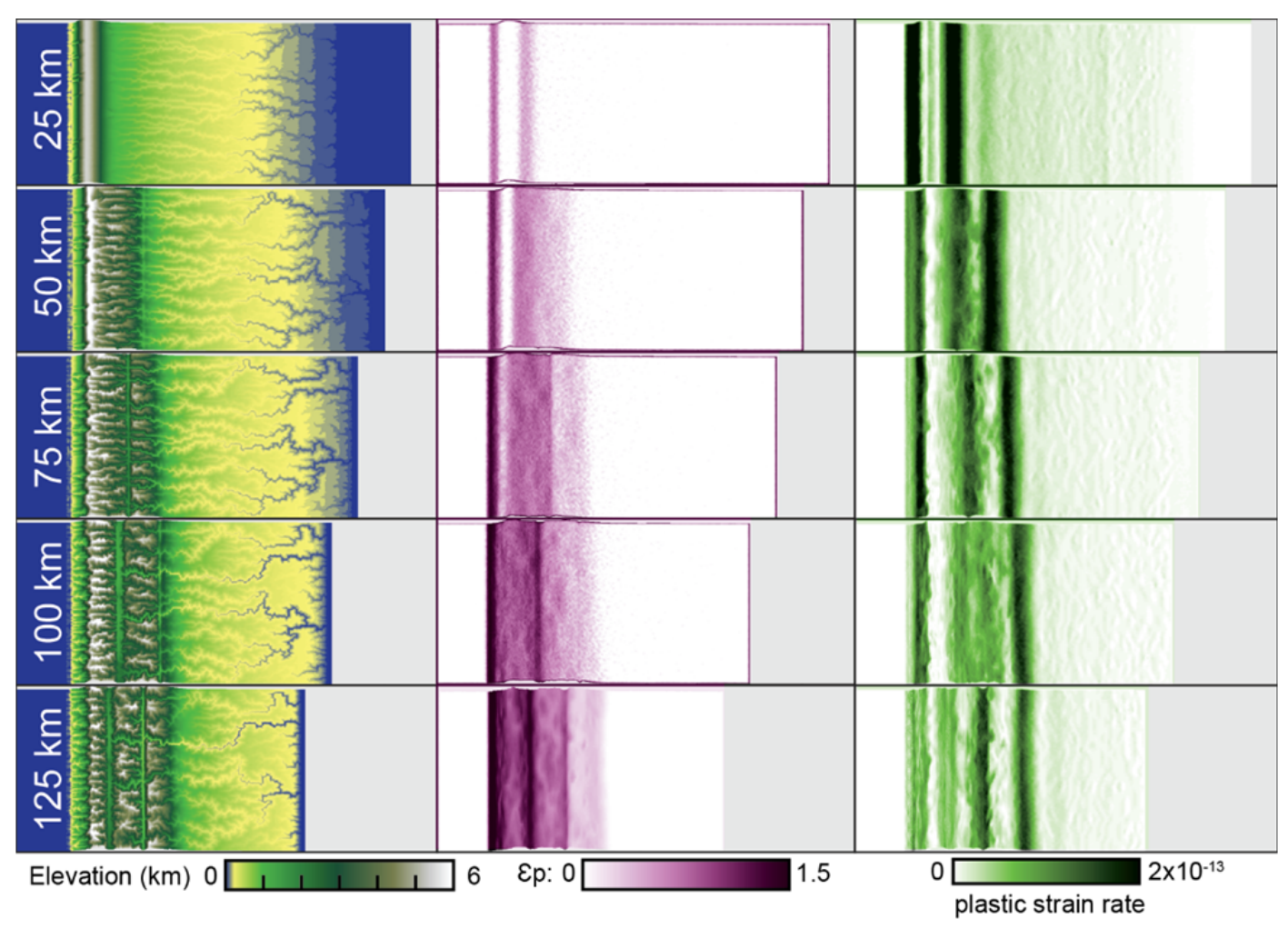

Figure DR3: Experiment 30X supplemental data. By row: 25, 50, 75, 100, $125 \mathrm{~km}$ convergence. By column: elevation, total plastic strain $\left(\varepsilon_{\mathrm{p}}\right)$, instantaneous strain rate. 


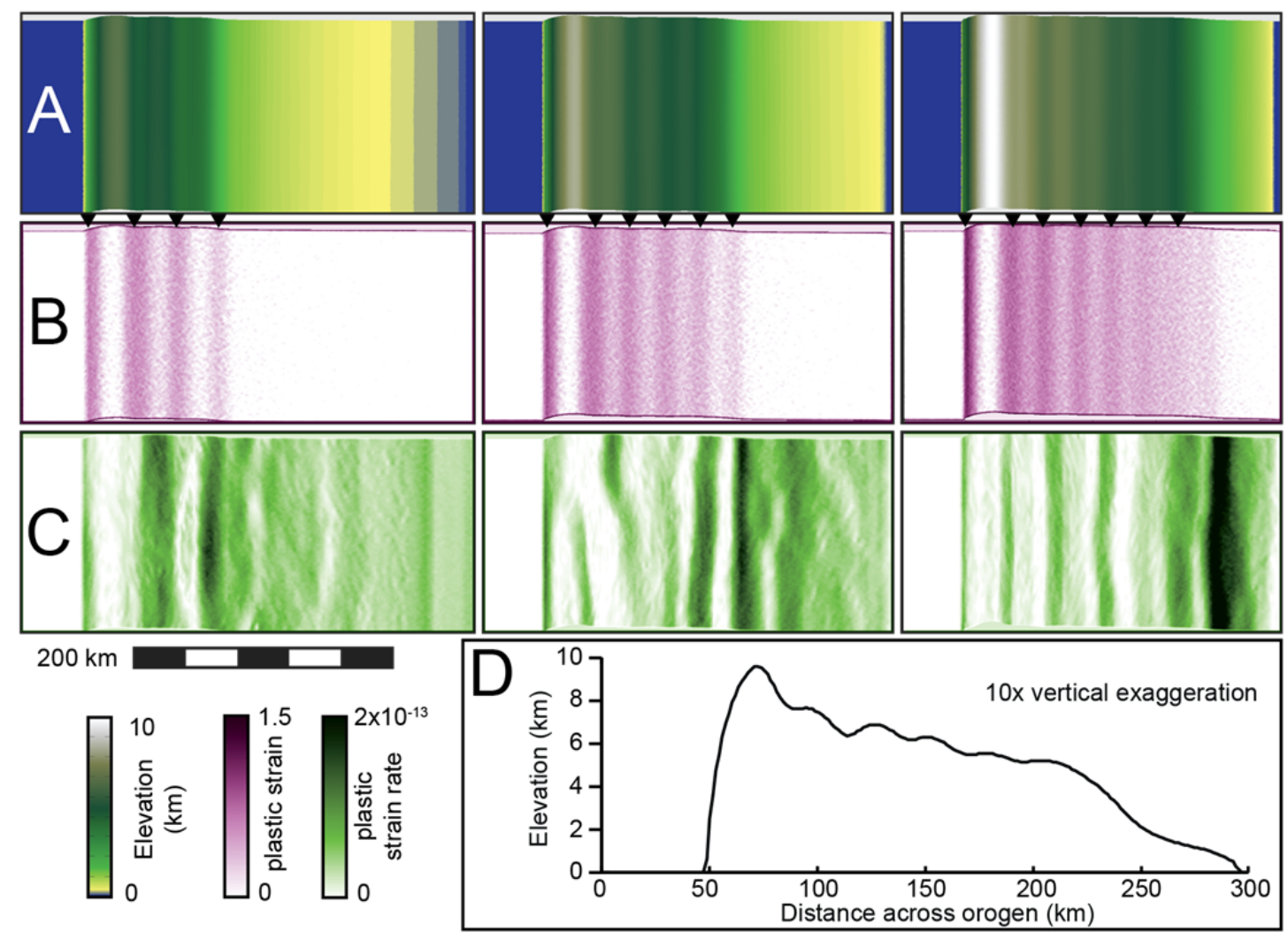

Figure DR4: Experiment rheologically identical to $1 \mathrm{X}$ and $30 \mathrm{X}$ but with no erosion: (A)

Topography, (B) total plastic strain $\left(\varepsilon_{\mathrm{p}}\right),(\mathrm{C})$ instantaneous strain rate, and (D) Elevation profile (please note the change in elevation scale compared to Figure DR1). From left to right, surfaces from $50 \mathrm{~km}, 75 \mathrm{~km}$, and $100 \mathrm{~km}$ of crustal shortening. Arrowheads indicate the location of shear zones. Color scales located at lower left. In this experiment, the convergent plate shortens laterally upon collision with the elastic plate leading to vertical displacement of the free surface (Figure DR4A, D). A decollement forms along the rheological boundary where strain is greatest. Plastic shear strain is transferred to the stronger mid and upper crustal layers. The rheological response in the upper crust localizes strain in shear zones. These shear zones form iteratively with increasing distance from the plate boundary (Figure DR4B). The shear zones host relatively large strain rates, but the greatest strain rate occurs along the growing eastern boundary of the orogen (Figure DR4C). As a consequence, surface deformation takes the form of low amplitude 
fold-thrusts that grow outward from the indentor collectively in a wedge shape. This deformation pattern is similar to the fold-and-thrust belts and submarine accretionary complexes that generally follow critical wedge theory (Davis et al., 1983; Dahlen, 1984). Due to a lack of precipitation and erosion there is no river network pattern.

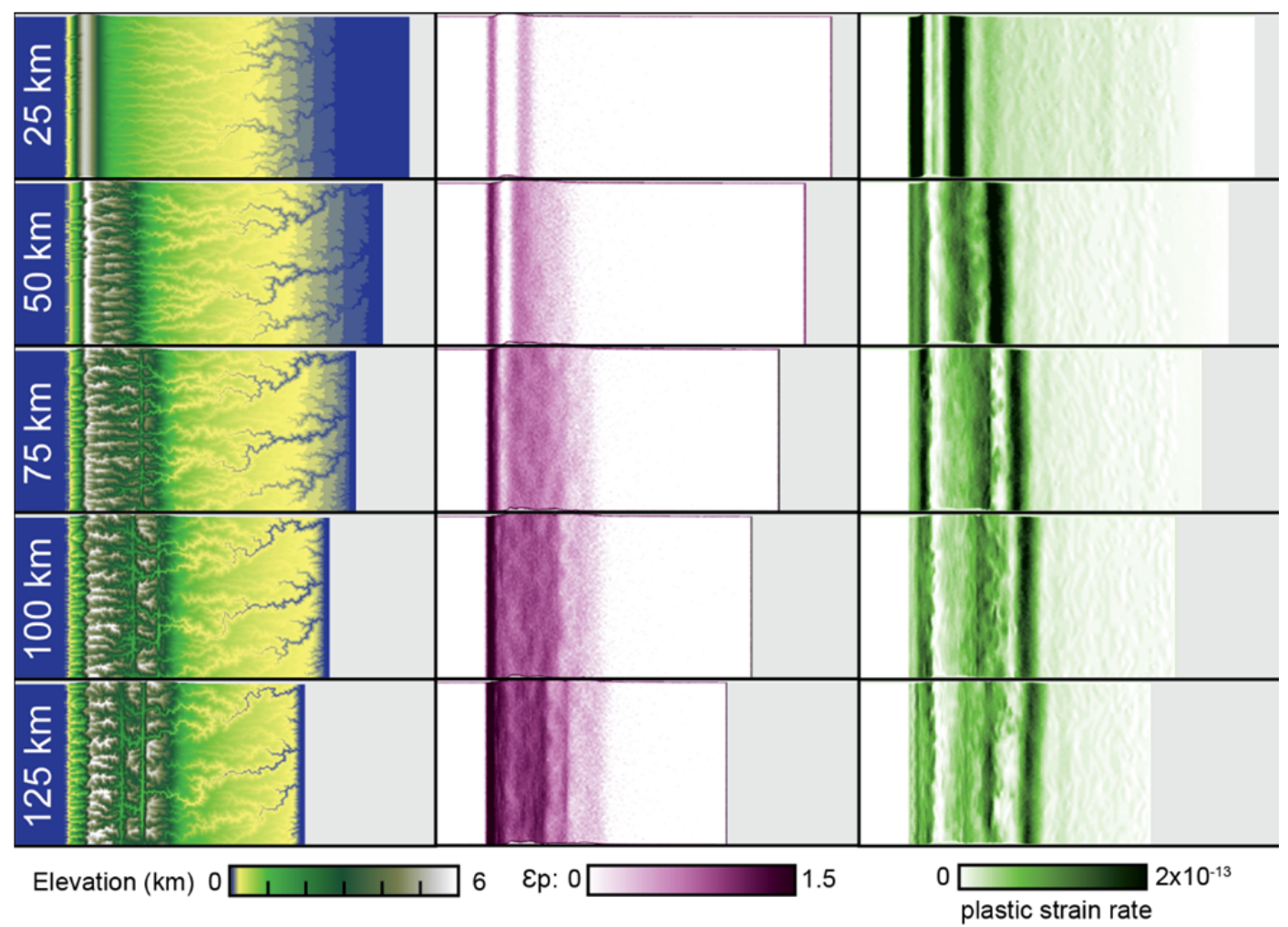

Figure DR5: Experiment 15X supplemental data. By row: 25, 50, 75, 100, $125 \mathrm{~km}$ convergence. By column: elevation, total plastic strain $\left(\varepsilon_{\mathrm{p}}\right)$, instantaneous strain rate. Note that there is a mixture of dendritic and structural drainage patterns within the orogen, leading to a larger number of dendritic rivers crossing shear-weakened zones and fewer large rivers confined to the structures as compared to the $30 \mathrm{X}$ experiment. 


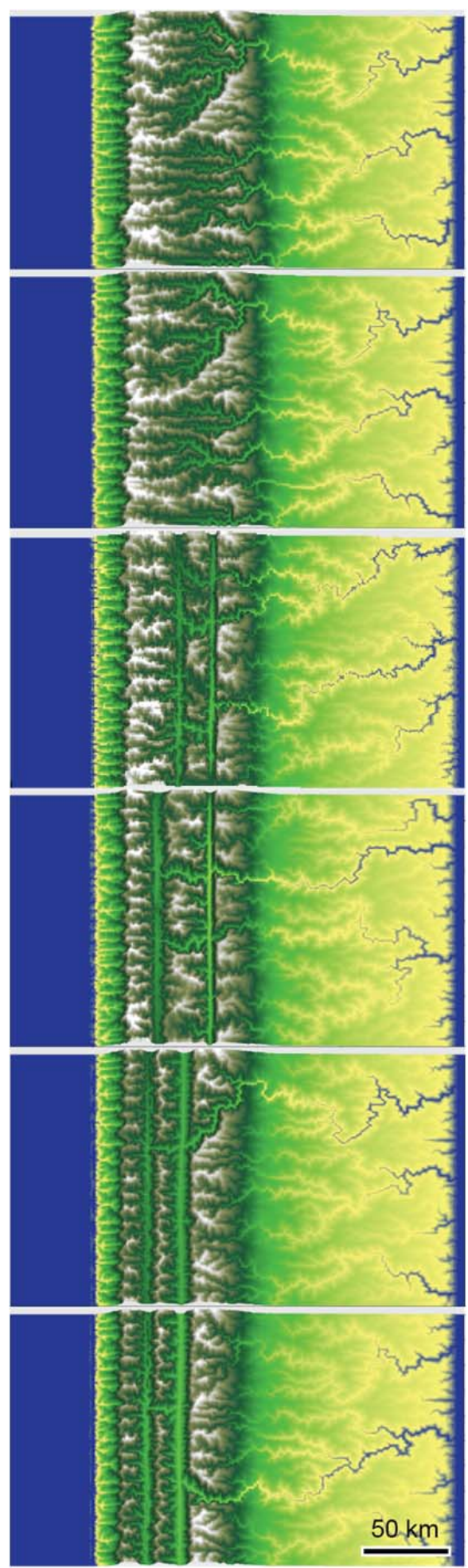

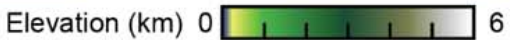

Figure DR6: Elevation for (from top to bottom) 1X, 3X, 30X, 300X, 3000X experiments, all after $125 \mathrm{~km}$ of convergence. 


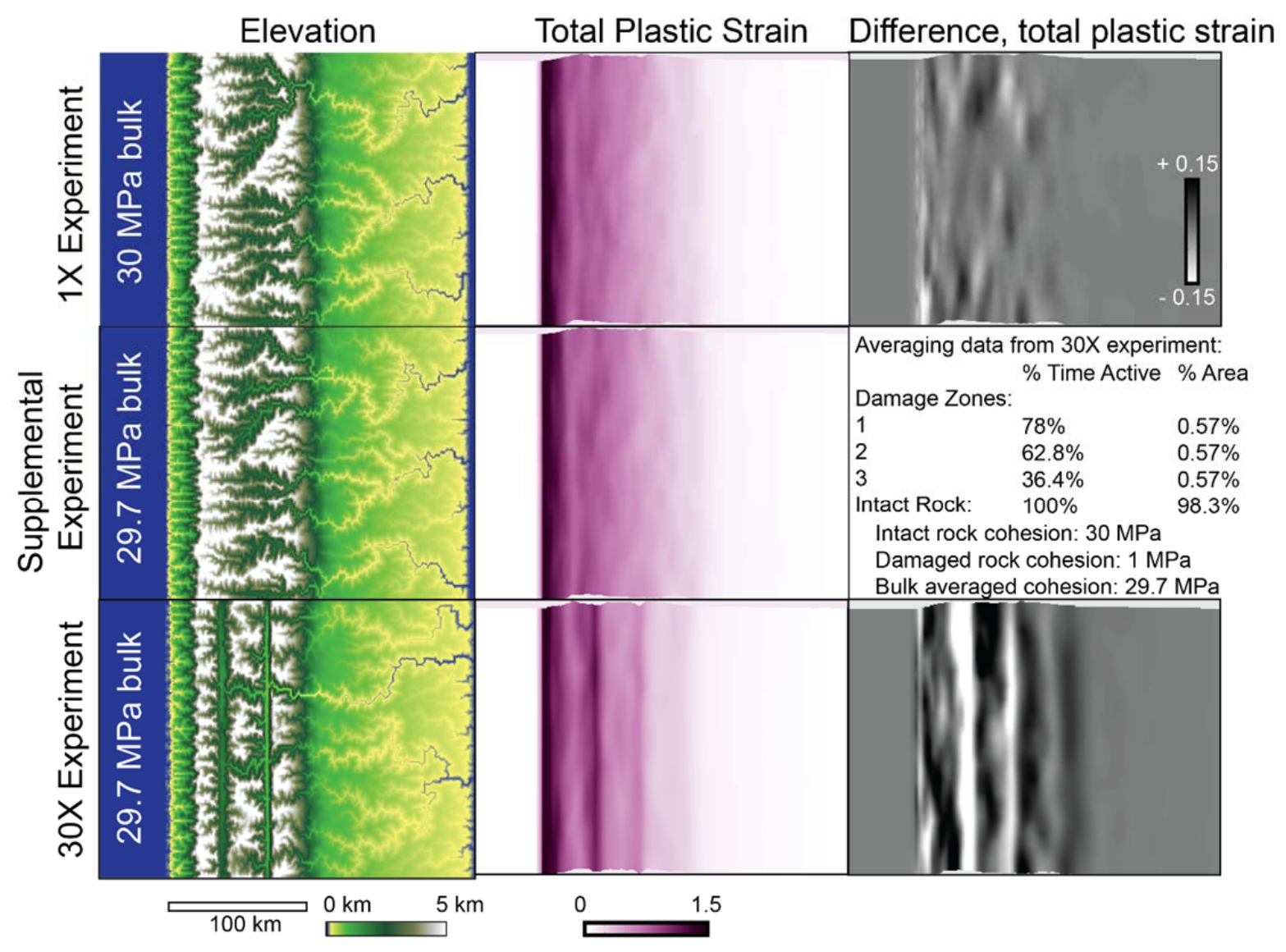

Figure DR7: Comparison to determine the relative importance of the bulk reduction in rock strength associated with shear damage versus the pattern of damage in controlling orogen width and strain localization. A supplementary model is provided with uniform cohesion equal to the bulk average cohesion from the $30 \mathrm{X}$ experiment, averaged over time and surface area. The damage zones that emerged in the $30 \mathrm{X}$ experiment reduced cohesive strength locally in $2 \mathrm{~km}$ wide zones for only a finite amount of time. Conversely, the area of intact rock remains dominant over the entire model duration. See table on right for details on averaging data. First column on left top to bottom: elevation for $1 \mathrm{X}(30 \mathrm{MPa})$ experiment, supplemental experiment with a uniform cohesion (29.7 MPa) equal to the time and area averaged cohesion of the $30 \mathrm{X}$ experiment, and the $30 \mathrm{X}$ experiment. Orogen widths are nearly identical between the $1 \mathrm{X}$ experiment and the supplemental experiment, while the $30 \mathrm{X}$ experiment has a slightly narrower width. Middle column (top to bottom): total plastic strain for $1 \mathrm{X}$ experiment, supplementary experiment, and 30X experiment. Last column (top to bottom): difference in total plastic strain, 
taken by subtracting the supplemental experiment by the $1 \mathrm{X}$ experiment, and by subtracting the supplemental experiment by the $30 \mathrm{X}$ experiment. There are a number of small differences in total plastic strain between the $1 \mathrm{X}$ and supplemental experiments that are probably caused by local topographic effects, but no large scale differences in total plastic strain distribution exist. There are significant orogen-scale differences in strain localization between the $30 \mathrm{X}$ and supplemental experiments. From these results we suggest that the pattern and concentration of shear damage plays a significantly larger role in controlling orogen width and strain localization than the bulk effect on strength reduction across the entire orogen.

\section{X Experiment}

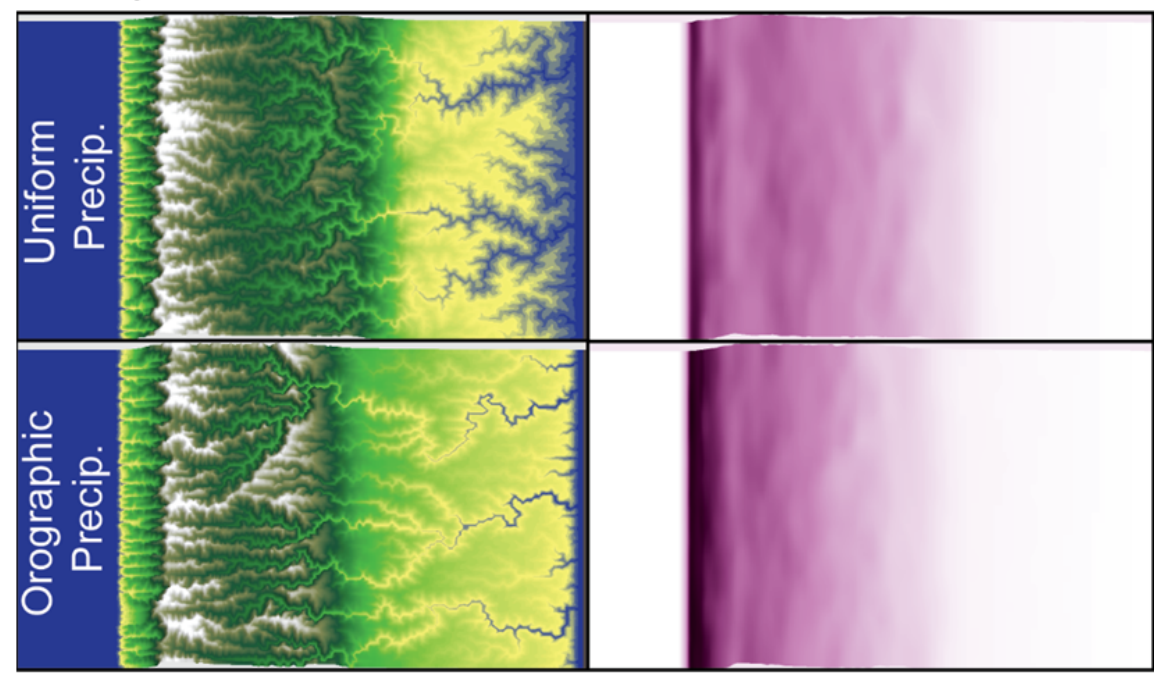

30X Experiment

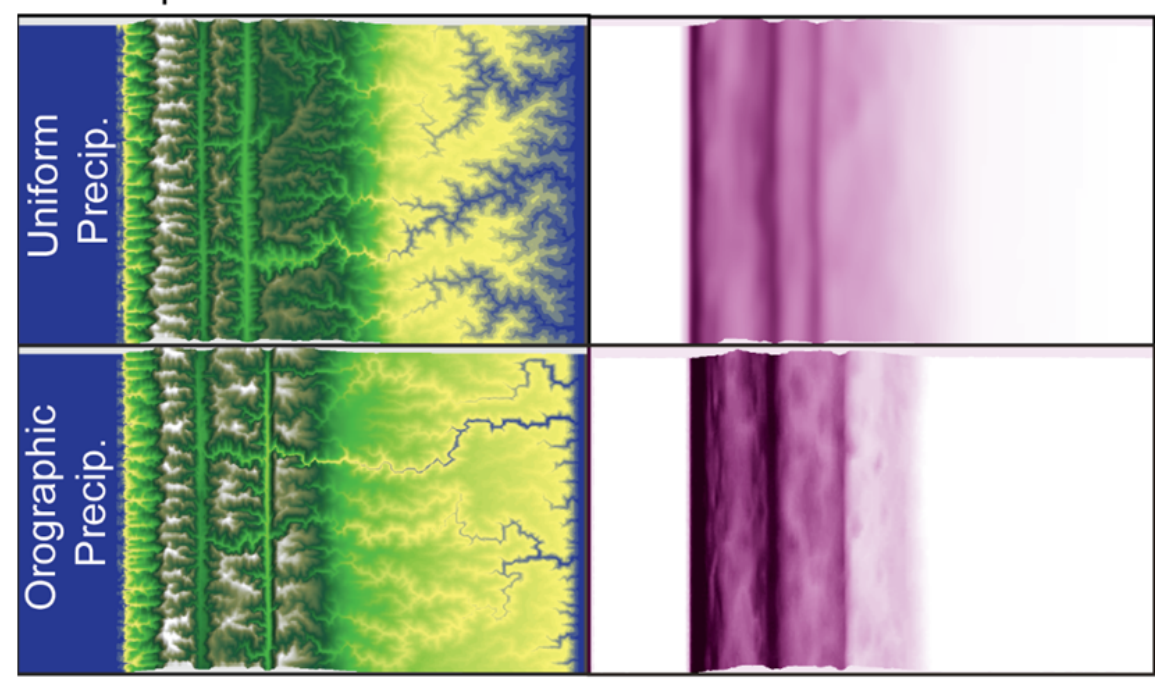

Elevation $(\mathrm{km}) 0$ 6 Ep: 0 
Figure DR8: Comparison of elevation (left) and total plastic strain (right) created under uniform, constant precipitation and orographic precipitation. The orographic precipitation model generates a majority of rainfall, and therefore stream power, along the western side of the orogen, which leads to a greater amount of eastward divide migration and generally lower elevation along the divide. The uniform precipitation model provides a greater amunt of precipitation along the eastern side of the orogen, leading to a net decrease in elevation along the eastern flank, but less precipitation along the western flank and the divide. The net increase in stream power along the eastern flank leads to greater gravitational unloading and a subsequently wider orogen, with a more distributed pattern of plastic strain. However, in both the $1 \mathrm{X}$ and $30 \mathrm{X}$ experiments, the drainage network patterns do not diverge from dendritic, range-perpendicular (1X) and structural, range-parallel (30X). Additionally, the pattern of strain localization emerges in the $30 \mathrm{X}$ experiment regardless of the pattern of precipitation, suggesting that the pattern of precipitation has a primary influence on gross topographic shape, but has only a secondary influence on drainage network patterns and the ability for heterogeneous rock strength to localize strain.

Video DR 1: elevation, experiment $1 \mathrm{X}$

Video DR 2: strain rate, experiment $1 \mathrm{X}$

Video DR 3: elevation, experiment 30X

Video DR 4: strain rate, experiment 30X 